\title{
Fluid migration in faulted shale rocks: channeling below active faulting threshold
}

\author{
Frédéric-Victor Donzé $e^{a^{*}}$, Alexandra Tsopela ${ }^{\mathrm{a}}$, Yves Guglielmi ${ }^{\mathrm{b}}$, Pierre \\ Henry ${ }^{\mathrm{c}}$ and Claude Gout ${ }^{\mathrm{d}}$ \\ ${ }^{a}$ Univ. Grenoble Alpes, Univ. Savoie Mont Blanc, CNRS, IRD, IFSTTAR, ISTerre, \\ 38000 Grenoble, France ;
}
${ }^{b}$ Lawrence Berkeley National Laboratory, Earth and Environmental Science Area, 1 Cyclotron road, M/S 74R316C, Berkeley, CA 94720;

${ }^{C}$ CEREGE, Aix-Marseille University-CNRS-IRD, Marseille, France ;

${ }^{d}$ Total S.A., Pau, France.

*Correspondence to: frederic.donze@univ-grenoble-alpes.fr.

\begin{abstract}
During fluid injection tests performed inside the clay-rich Tournemire fault zone, the monitored fault displacement exhibited limited amplitudes whereas a sharp increase of the permeability occurred as the fluid pressure reached a threshold value. The injected fluid channeled through the fractured zone or at the interface between the host rock and the fault core over decameter distances without triggering large irreversible deformation of the fault zone. To assess the underlying hydro-mechanical mechanisms of this sudden increase of permeability, a numerical model was set up to simulate an injection test inside a fracture. When the fluid pressure outweighs the mechanical contribution of the heterogeneities along the fracture planes, the sudden increase of permeability appears. The existence of the channeling process, occurring below a critical fluid pressure at the fracture scale, could explain why it is possible to generate fault leakage inside a non-active fault zone crossing shale rocks. Based on the in-situ and laboratory monitoring, an analytical expression based on TPHM (Two-Part Hooke's Model) can reproduce the stress-dependent permeability evolution. For low values of the effective stress, a simple cubic law formulation does not reproduce correctly the sharp increase of permeability identified once the Fracture Opening Pressure (FOP) is reached.
\end{abstract}

Keywords: pressurized fault; fluid flow path; stress-dependent permeability; discrete element model; fault strength; critical fluid pressure

\section{Introduction}

Faults seal capacities and their potential contribution on the fluid migration have been mostly characterized based on geochemical or mineralogical formulations [Jones and Hillis, 2003; Mildren et al. 2004]. If dissolution, mineralization or diffusion processes may play a long term role on the seal capacity for shale rocks, the stress environment related to the possible over-pressurization of the fluid can dramatically increase the permeability in a short time scale [Haney et al., 2005b; Finkbeiner et al., 2001]. Quantifying the contribution of the in-situ stress state to permeability changes, while considering the fluid pressure, implies that there is a minimum knowledge available on hydro-mechanical properties of the geological structures, which includes the 
characterization of the inherited fracture sets or the presence of fault zones [Hao et al., 2015]. These fault zones, generally considered as fluid crossing barriers, can act as drain in some given stress and pressure conditions along them [Wiprut and Zoback, 2000]. From a geomechanical point of view, which considers the effective stress formulation of the problem, a basic concept is that the action of mechanical instabilities induce a change of several orders of magnitude of the permeability values [Gutierrez et al., 2000; Hawkes et al., 2004; Hao et al., 2015]. This leads to preferential paths for the fluid migration [Ligtenberg, 2005]. The main mechanical instabilities that may be responsible for these fluid leakages in caprock formation crossed by faults are [Sukhla, et al., 2010]:

- Shear or open failure of the intact but generally stratified or laminated shales,

- Reactivation of fracture or joint sets present within the damage zone of the fault,

- Reactivation of the interface between the fault core and the damage zone.

Based on these different mechanisms, conceptual and quantitative models can express the hydro-mechanical conditions for which the instabilities and irreversible behavior is reached. Among different models, Finkbeiner et al. [2001] introduced the concept of dynamic capacity model to describe the in-situ effective stress state that may control the fluid migration by enhancing fracture permeability at the reservoir or fault scale. The onset of fluid migration can be related either to a hydraulic fracturation, when fluid pressure reaches the minimum in-situ stress or to a shear fracture reactivation, when the fluid pressure reaches a value corresponding to the critical effective stress activating the shear failure. The key point is that this type of model suggests a direct relationship between an irreversible mechanical response of the fault zone and a substantial variation of the permeability.

However, the fault destabilization does not always occur during fluid migration. Recent field studies suggest that taking into account subcritical mechanical response may be required to explain why the permeability of a fault zone can increase by a factor of 10100 up to $100 \mathrm{~m}^{2}$ when increasing the fluid pressure during injection tests. While strain records do exhibit generally only local and very low plastic deformation [Guglielmi et al., 2015]. The fluid injection tests performed inside a clay-rich fault zone at the Tournemire IRSN underground laboratory exhibited such mechanical responses [Guglielmi et al., 2017]. These injection tests were part of the "Fluids and Faults" project [Henry et al., 2016], which was undertaken to constrain and better understand the relationship relating permeability, pressure, stress and strain in fault zones in shale for application to basin and reservoir modeling. The project included (i) in situ injection tests (ii) laboratory experiments on core samples [Bonnelye et al., 2017] and (iii) seismic monitoring of the injection tests [Rivet et al., 2016; De Barros et al., 2016]. Based on the results obtained from this highly monitored project, we have set up a numerical model to investigate the hydro-mechanical conditions in which the flow rate and permeability increase dramatically depending on the fluid pressure while the mechanical response of the hydraulically loaded zones, exhibits a relatively minor irreversible strain response. The model presented here is a conceptual model aiming to explain the permeability along faults in clay formations from observations that were not reproduced by earlier modeling work and based on the Tournemire field experiments [Guglielmi et al., 2015; Tsopela et al., 2019]. Its purpose is not to reproduce the exact geometry of the pressure and strain field around the injection borehole, but to help understand the relationship obtained between injection pressure and permeability. The experiments showed permeability increases sharply before the (average) normal stress drops to zero and without large 
irreversible shear strains. On the other hand, the apparent reversibility of shear strains [Guglielmi et al., 2015; Tsopela et al., 2019, Rivet et al., 2016] precludes large scale shear failure of the fault plane. We first discuss the possibility that fluids are transiently channeling within the connected fractures forming the damage zone of the fault zone before this sharp increase of the permeability. We hypothesize that heterogeneities allow local failure and fluid channeling in the fault zone without triggering large scale failure, and propose a generic model with simplified boundary conditions and geometry. Based on this concept, we then derive general analytic relationships to reproduce the evolution of the stress-dependent permeability exhibiting a sharp increase for low effective stress values.

\section{Tournemire in-situ experimental tests}

A series of experiments using the SIMFIP Probe [Guglielmi et al., 2015] were performed within a fault zone in a very low permeable formation (less than $10^{-19} \mathrm{~m}^{2}$ ), inside the lower Jurassic shale at the Tournemire Underground Research Laboratory (URL), France. The objective was to monitor the response of a fault in low permeability shales subjected to fluid injection with borehole strain sensors, an array of acoustic and seismic sensors and a resistivity-imaging probe. The Tournemire shale displays strong anisotropic mechanical properties [Bonnelye et al., 2017] and contains up to $60 \%$ of phyllosilicates (smectite, illite, kaolinite, chlorite, and mica), less than $20 \%$ of quartz and around $20 \%$ of carbonate [Tremoza et al., 2012]. The shale has a low porosity, from $8 \%$ to $12 \%$, corresponding to a water content of 3.5 to $5 \%$ weight at saturation and a hydraulic conductivity of $10^{-14}$ to $10^{-15} \mathrm{~m} / \mathrm{s}$ measured on core samples in the laboratory [Boisson et al., 2001].

The injection experiment and the installation of sensors (hydro-mechanical, seismic and electric) required drilling several boreholes across the fault zone (Figure 1). The injection experiments took place in a $30 \mathrm{~m}$ long and $0.146 \mathrm{~m}$ diameter borehole drilled from the Tournemire tunnel and inclined at $21^{\circ} \mathrm{E}$ to intersect perpendicular to the fault. The injection tests targeted different zones where fractures sets were identified in the fault zone, mentioned as "fracture damage zones" (Brownish zones in Figure 1 bottom). The state of stress was estimated as a strike/slip regime with the maximum stress $\sigma_{1}$ being horizontal, oriented $\mathrm{N} 162^{\circ} \pm 15^{\circ} \mathrm{E}$ and equal to $4 \pm 2 \mathrm{MPa}$. The intermediate stress $\sigma_{2}$ is equal to $3.8 \pm 0.4 \mathrm{MPa}$, and it is the vertical component with a plunge $83-82^{\circ}$ and azimuth $\mathrm{N} 072^{\circ}$. The stress $\sigma_{3}$ is the minimum horizontal stress equals to $2.1 \pm 1 \mathrm{MPa}$ with a plunge $7-80^{\circ}$ and azimuth $\mathrm{N} 072^{\circ}$. The directions of the horizontal stresses are shown in Figure 1 (bottom).

The apparatus used for the fluid pressurization was composed of surface equipment to conduct the test and acquire the data, and a probe [Guglielmi et al., 2013] (Figure 2). The probe monitors 3D displacement between two points anchored to the borehole walls at the same time as fluid pressure and flow rate. The SIMFIP test is a combination of short duration pulses and a long duration pressure "step-up" and "step-down" step-rate tests. Test duration depends on the permeability of the formation [Guglielmi et al., 2013]. 

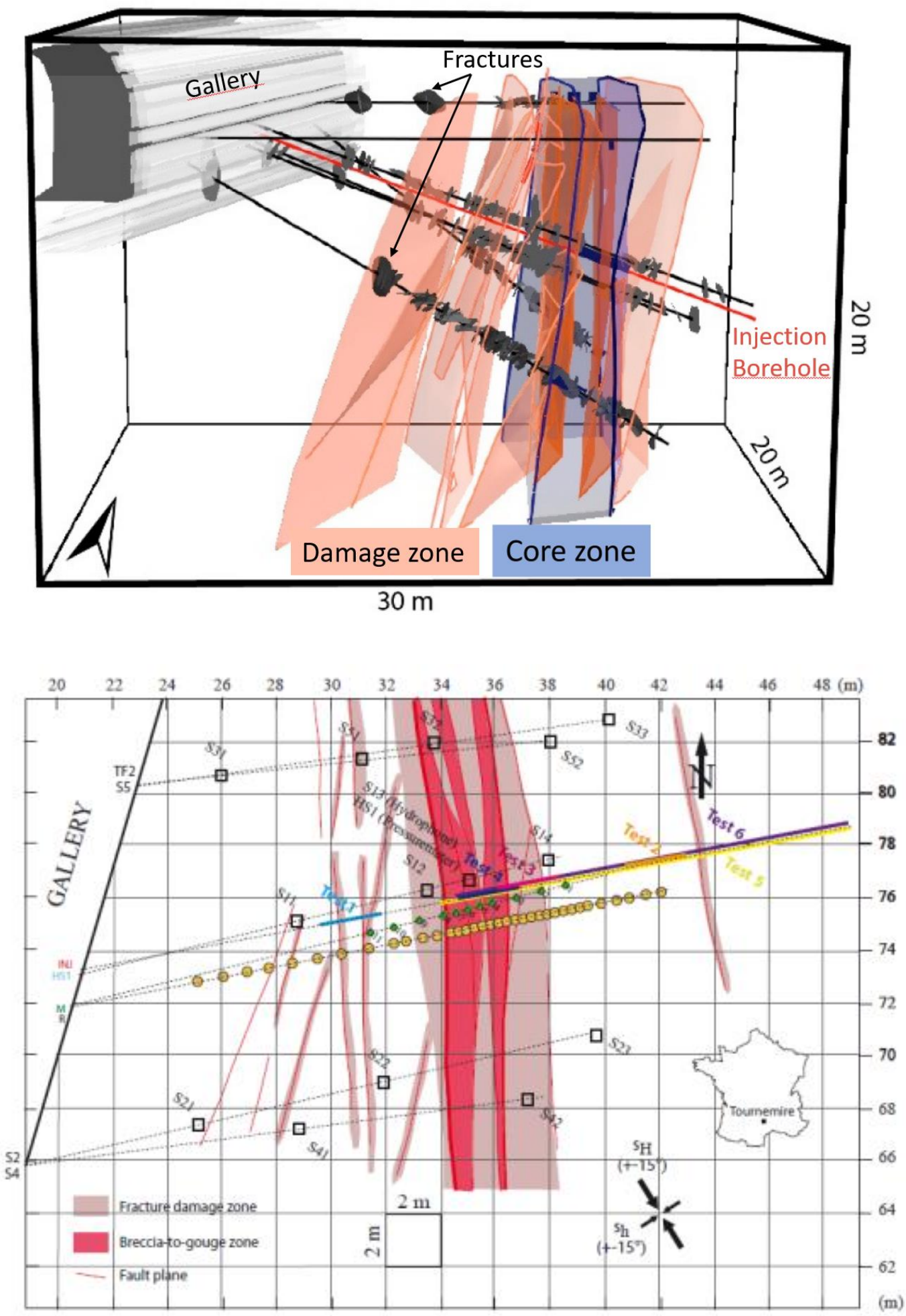

Figure 1. Top: A 3D view of the fault zone including the seven monitored boreholes. The pink line corresponds to the borehole containing the SIMFIP probe [Lefèvre et al., 2016]. Bottom: Horizontal cross section of the instrumented experimental site. The locations of the different tests are shown along the injection borehole and different colors. The orange dots correspond to strain sensors, the green dots to resistivity sensors and squares correspond to seismometers [De Barros et al., 2016]). 
The pulse pressure magnitude is below the 'fracture extension pressure' to characterize the fracture hydro-mechanical elastic response. Then, during the "step-up" step-rate test, the water is injected at a low pressure for a given duration. The injection pressure is incremented and held constant, typically for the same duration. This is repeated while the deformations across the fault with the 3D deformation probe is monitored.

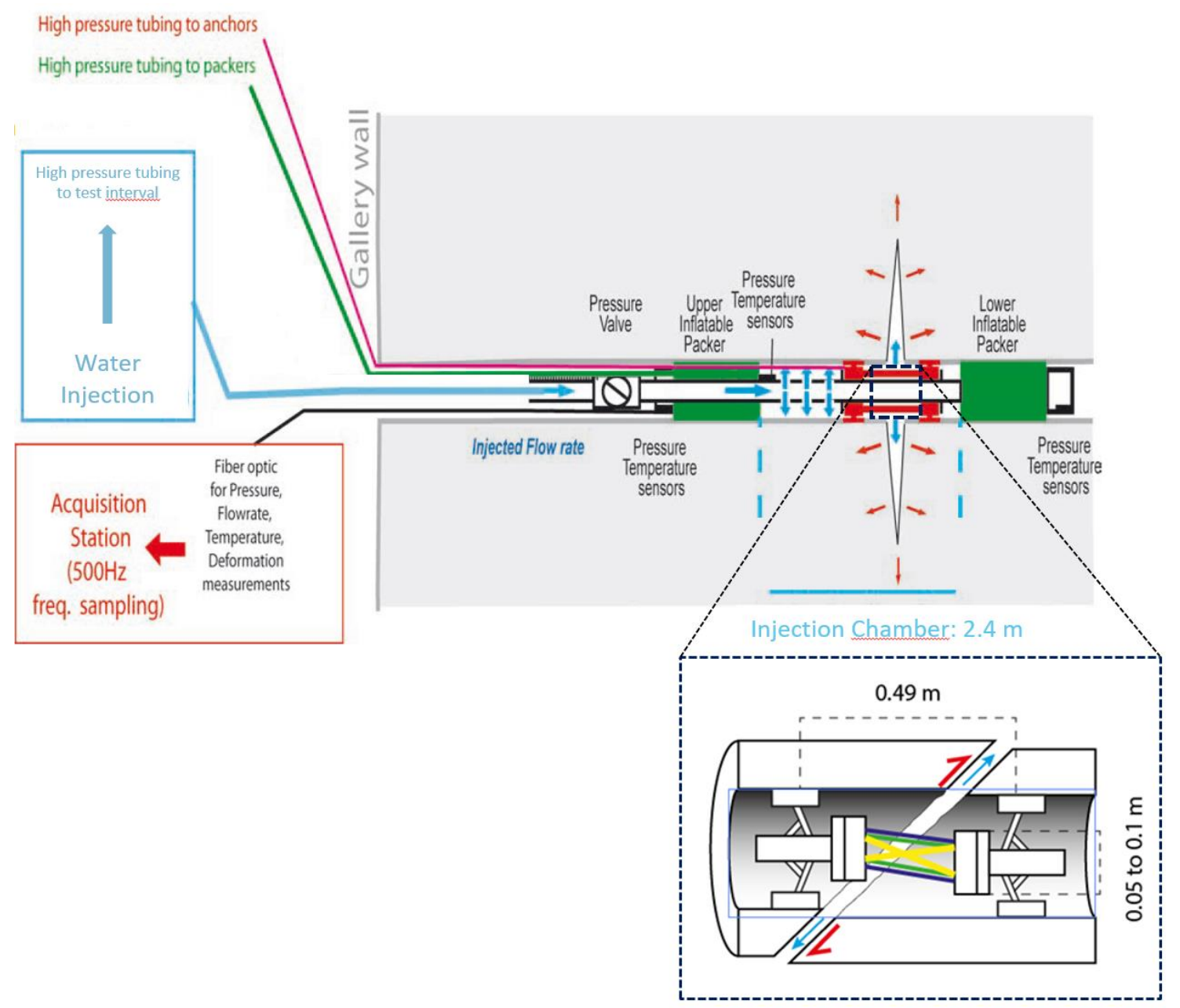

Figure 2. Schematic view of the SIMFIP probe with its injection chamber (Top). The SIMFIP device is a carved cylinder made of aluminum material and the six components of the deformation are measured with a six fiber Bragg grating system which can capture the full displacement tensor of a pressurized fracture whatever its orientation (Bottom) [Guglielmi et al., 2015].

After reaching a threshold pressure, a large increase in flow rate at constant pressure occurred. Several series of tests were carried out and in all of them the transmissivitypressure dependency exhibited a substantial increase (more than $100 \mathrm{~mL} / \mathrm{min}$ ) only above this pressure threshold which has been called the Fault Opening Pressure (FOP) [Henry et al., 2016] (Figure 3). It was observed that (i) fracture opening (axial displacement) was always associated to shear displacement, (ii) the hydraulic opening occurred below the in-situ minimum stress $\sigma_{3}$ and (iii) a significant part of the deformation associated with the hydraulic opening appeared to be associated with only a low level of irreversible displacement, of a maximum order of a hundred of micrometers. Similar observations 


\section{November 2019}

were obtained using similar tests carried out at the Mont Terri Main fault zone affecting shale layers [Nguyen et al., 2019]: high leakage potential were induced by relatively low infra-millimeter slip movements with a low level of irreversibility [Rivet et al., 2016].

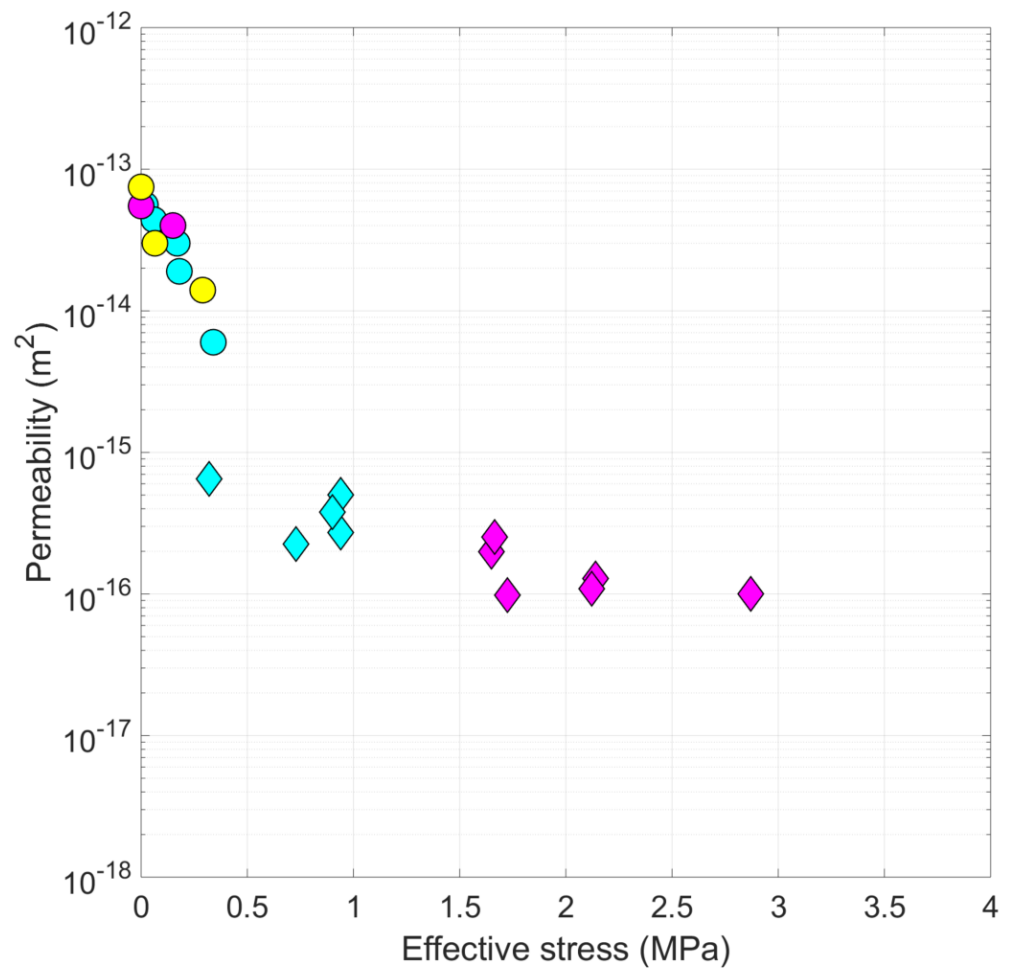

Figure 3. Permeability as a function of pressure in the injection borehole relative to the effective stress for tests 1 (cyan), 3 (magenta) and 5 (yellow), see Figure 1, for the respective location of these tests. The circles correspond to the "step-up" step-rate tests and the diamonds to the pulse tests. The FOP corresponds to an effective stress around $0.6 \mathrm{MPa}$ for a resulting injection flow higher more than $100 \mathrm{~mL} / \mathrm{min}$. tests.

Several observations from the Tournemire experiments indicated that the water flow was channelled because fluid flow from the injection borehole appeared asymmetric as shown by geophysical anomalies [Rivet et al., 2016], leakage through boreholes and tunnel EDZ dozen of meters away from the injection point, and micro-seismicity, which occurred exclusively South of the injection borehole [De Barros et al., 2016].

Two main hydro-mechanical thresholds were identified from these injection tests on preexisting fractures. These are a minimum Fracture Pressure, which corresponds to the first deviation from a linear elastic behavior of the borehole walls and, the Formation Opening Pressure (FOP), which corresponds to the hydraulic opening of the formation beyond which fluid injection can be sustained with a steady flow rate (more than $100 \mathrm{~mL} / \mathrm{min}$ ). There is evidence that channeling of the fluid into the formation occurs between the two thresholds, as well as opening and shear on fractures intersected by the borehole to a distance of at least $1 \mathrm{~m}$. 


\section{Numerical modeling}

To reproduce the conditions under which the FOP occurs, a discrete element model was set up using the three-dimensional software 3DEC [Itasca C. G., 2015]. The rock mass is modeled as an assemblage of discrete blocks with the discontinuities representing the boundary conditions between the deformable blocks. The model consists of a $2 \mathrm{~m}$ cube cut by a single sub-vertical fault oriented $\mathrm{N} 171^{\circ} / 86^{\circ} \mathrm{W}$ with a prescribed response that follows the Coulomb criterion for the reference configuration. The surrounding intact material is elastic and impermeable. Hence, flow is only occurring along the fault plane and strictly along the parts of the plane that have failed either in shear or in tension. The stress field applied is in the range of the in-situ stress values in the case of the Tournemire fault experiments [Guglielmi et al., 2015; De Barros et al, 2016]. Similarly, the orientation of the fault plane corresponds to the main orientation of the Tournemire fault [Tsopela et al., 2016; Guglielmi et al., 2015].

Previous models assuming a single and homogeneous slipping plane could well reproduce data during the first steps of the pressurization tests associated to the hydraulic opening of the Tournermire tests [Tsopela et al., 2019; Guglielmi et al., 2015], but they remained limited to explain the observed FOP associated to a low plastic response. Models considering fracture interactions might also partly explain the limited irreversibility of the slip movement [Rivet et al., 2016] but they refer to a complex and very specific spatial organization of the fracture set. Taking into account the in-plane heterogeneities can also explain the observed FOP while explaining explicitly the channeling of the fluid for higher effective stress [Cornet et al., 2003; Dick et al., 2016]: this is our present hypothesis.

In the set up numerical model, heterogeneities along the fault plane have been considered in terms of mechanical properties. We justified this approach because the shear displacement amplitude remained small compared to the size of the heterogeneities. This hypothesis is not valid when this condition is not met anymore. The model's geometry together with the applied stresses is presented in Figure 4a. For comparison, four different degrees of heterogeneities have been generated. The first one (case 1-black in Figures 5 and 6) involves a homogeneous plane with a constant friction angle of $15^{\circ}$ that has been assigned on the overall fracture plane without any cohesion or tensile strength. In the other three configurations, heterogeneities, i.e. asperities have been introduced along the fracture surface by selecting in a random manner different zones representing $50 \%$ of the total surface. The spatial distribution of these heterogeneities or asperities along the plane, are represented by the black zones in Figure 4a,b. In the second configuration (case 2green), asperities have a friction of $40^{\circ}$, in the third one (case 3-purple), the friction is still $40^{\circ}$ with an added cohesion of $1 \mathrm{MPa}$ and for the last configuration (case 4-orange), a tensile strength of $1 \mathrm{MPa}$ is added (see Table 1). 
Table 1. Boundary conditions and material properties of the Discrete Element Model.

\begin{tabular}{|c|c|}
\hline Size of the model & Boundary conditions \\
\hline $2 \mathrm{~m} \times 2 \mathrm{~m} \times 2 \mathrm{~m}$ & $\begin{array}{l}\text { - Zero velocity at boundaries } \\
\text { - Lateral impermeable boundaries } \\
\text { - Stress field: } \\
\text { - } \sigma_{\mathrm{x}}=-4.9 \times 10^{6} \mathrm{~Pa}, \sigma_{\mathrm{y}}=-3.9 \times 10^{6} \mathrm{~Pa}, \sigma_{\mathrm{z}}= \\
\\
-4.1 \times 10^{6} \mathrm{~Pa} \\
\text { - } \text { Initial fluid pressure: } \mathrm{pp}=0.2 \times 10^{6} \mathrm{~Pa}\end{array}$ \\
\hline Properties of the rock matrix & Properties of the plane \\
\hline $\begin{array}{l}\text { - Density: } \rho=2500 \mathrm{~kg} / \mathrm{m} 3 \\
\text { - Young's modulus parallel to bedding: } \mathrm{E}_{1}= \\
\mathrm{E}_{2}=8.5 \times 10^{9} \mathrm{~Pa} \\
\text { - Young's modulus normal to bedding: } \mathrm{E}_{3}= \\
3.6 \times 10^{9} \mathrm{~Pa} \\
\text { - Poisson's ratio parallel to bedding: } \mathrm{v}_{12}= \\
0.33 \\
\text { - Poisson's ratio normal to bedding: } \mathrm{v}_{13}=\mathrm{v}_{23} \\
=0.33 \\
\text { - Shear modulus parallel to the bedding: } \mathrm{G}_{12} \\
=3.2 \times 10^{9} \mathrm{~Pa} \\
\text { - Shear modulus normal to the bedding: } \mathrm{G}_{13} \\
=\mathrm{G}_{23}=1.4 \times 10^{9} \mathrm{~Pa}\end{array}$ & $\begin{array}{l}\text { - Normal stiffness: } \mathrm{K}_{\mathrm{n}}=100 \times 10^{9} \mathrm{~Pa} / \mathrm{m} \\
\text { - Shear stiffness: } \mathrm{K}_{\mathrm{s}}=4 \times 10^{9} \mathrm{~Pa} / \mathrm{m} \\
\text { - } \text { Friction angle: } \phi=15^{\circ} \\
\text { - } \text { Cohesion: } \mathrm{c}=0 \\
\text { - Tensile strength: jtens }=0 \\
\text { - Hydraulic aperture at zero normal stress: } \\
\text { azero }=3 \times 10^{-5} \mathrm{~m} \\
\text { - Maximum hydraulic aperture: amax }=10^{-} \\
{ }^{3} \mathrm{~m} \\
\text { - } \quad \text { Residual hydraulic aperture: ares }=2 \times 10^{-} \\
{ }^{7} \mathrm{~m}\end{array}$ \\
\hline $\begin{array}{l}\begin{array}{l}\text { Properties of the heterogeneities } \\
\text { (asperities) }\end{array} \\
\text { (ast }\end{array}$ & Fluid properties \\
\hline $\begin{array}{l}\text { - Normal stiffness: } \mathrm{K}_{\mathrm{n}}=100 \times 10^{9} \mathrm{~Pa} / \mathrm{m} \\
\text { - Shear stiffness: } \mathrm{K}_{\mathrm{s}}=4 \times 10^{9} \mathrm{~Pa} / \mathrm{m} \\
\text { - } \\
\text { - } \text { Cohiction angle: } \phi=40^{\circ} \\
\text { cohesion: } \mathrm{c}=10^{6} \mathrm{~Pa} \text { (in the case of } \\
\text { - Tensile strength: jtens }=10^{6} \mathrm{~Pa} \text { (in the case } \\
\text { of tensional heterogeneities) } \\
\text { - Hydraulic aperture at zero normal stress: } \\
\text { azero }=3 \times 10^{-5} \mathrm{~m} \\
\text { - Max hydraulic aperture: amax }=10^{-3} \mathrm{~m} \\
\text { Residual hydraulic aperture: ares }=2 \times 10^{-} \\
7 \mathrm{~m}\end{array}$ & $\begin{array}{ll}\text { - } & \text { Bulk modulus: } \mathrm{K}_{\mathrm{f}}=2 \times 10^{9} \mathrm{~Pa} \\
\text { - } & \text { Density: } \rho_{\mathrm{f}}=1000 \mathrm{~kg} / \mathrm{m} 3 \\
\text { - } & \text { Dynamic viscosity: } \mu=1 \times 10^{-3} \mathrm{~Pa} . \mathrm{s}\end{array}$ \\
\hline
\end{tabular}

Based on the assigned properties, the higher resistance zones can represent either frictional heterogeneities such as gouge patches, contact areas or calcified zones along the fault plane [Lefèvre et al., 2016]. Regarding the size distribution of the heterogeneities, one could use a power-law distribution but since the model covers a narrow range of scale a uniform distribution has been used, securing that the connectivity of the low friction parts (white zones) is high enough to allow the fluid to cross the medium through them (Figure $4 b$ ). 
a)

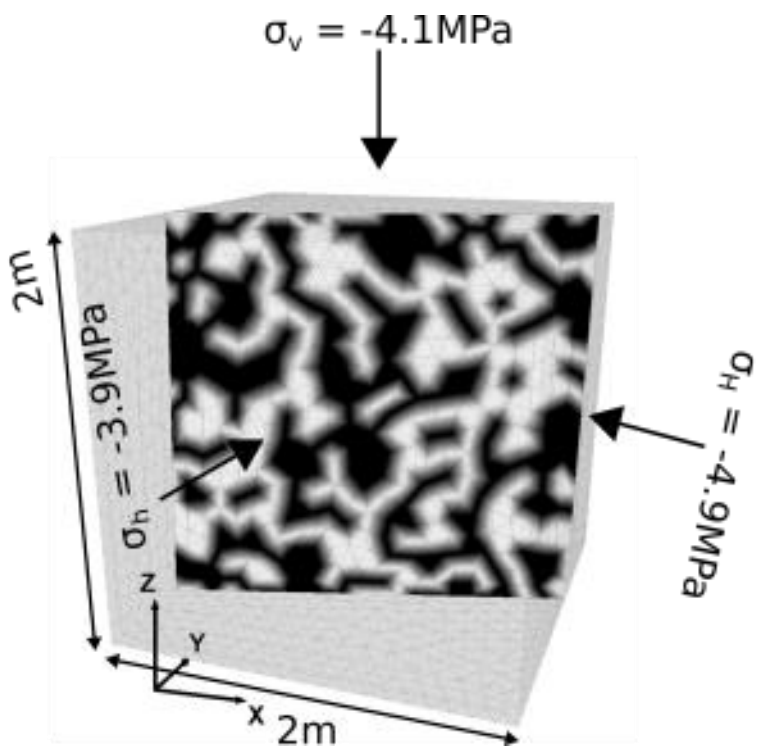

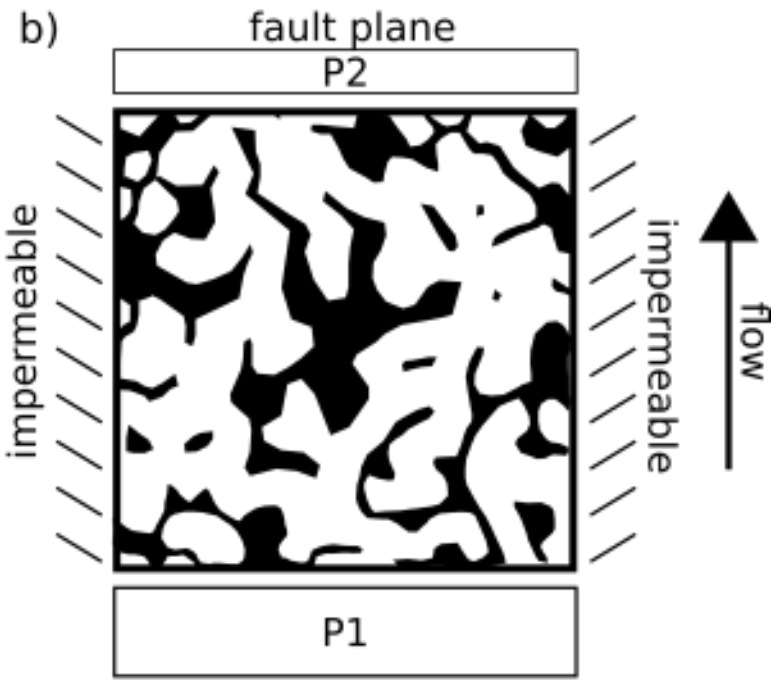

Figure 4. Geometry of the numerical model with the stress field applied and the distribution of the heterogeneities along the plane. The white areas represent low friction areas $\left(10^{\circ}\right)$ while the black areas represent the high friction areas $\left(40^{\circ}\right)$. (b) Hydraulic pressure applied at the boundaries with P1 higher than P2.

In order to calculate the failure envelopes for the heterogeneous configurations, a fluid pressure is applied uniformly over the whole plane for different stress states. When the fluid pressure is progressively increased, mechanical instabilities appear which ultimately leads to a general slipping process. The resulting failure envelopes are presented for the three different configurations in Figure 5. The points selected for each specific cases correspond to the effective stress value for which the totality of the plane fails under the given stress state. Lines crossing these different points were also drawn on Figure 5, in order to show the shape of the corresponding failure envelops.

The permeability measurements are performed as follow: after applying the in-situ stresses, a pore pressure is uniformly applied on the fracture plane. This pressure value corresponds to the fluid pressure for which the effective normal stress leads to the shear failure of the homogeneous configuration, i.e. with a friction angle of $15^{\circ}$ but not high enough to destabilize the plane in presence of the heterogeneities. Then, an entrance and higher pressure $\mathrm{P} 1$ is applied at the bottom of the model resulting in an imposed hydraulic gradient as the exit pressure P2 is kept constant, i.e. corresponding to the initial and uniform fluid pressure while keeping the lateral boundaries impermeable. Then the flow rates at the bottom and the top of the model are calculated once a steady state flow regime is reached. The applied entrance pressure values $\mathrm{P} 1$ cover a range between $3 \mathrm{MPa}$ to 4.3 $\mathrm{MPa}$ while $\mathrm{P} 2$ remains always constant at $0.2 \mathrm{MPa}$. The equivalent permeability of the model domain is estimated using the following equation [Min et al., 2004]:

$$
k_{\text {in }}=\frac{Q_{\text {in }} \mu}{A_{\text {in }}} \frac{d x}{d P}=k_{\text {out }}=\frac{Q_{\text {out }} \mu}{A_{\text {out }}} \frac{d x}{d P}
$$

where $Q_{\text {in }}=Q_{\text {out }}$ are the flow rates calculated at the inflow and outflow boundaries respectively, $A_{\text {in }}=A_{\text {out }}$ are the cross-sectional areas of the inflow and outflow boundary faces respectively, $\mu$ is the dynamic viscosity of the fluid, $d P$ is the fluid pressure difference and $\mathrm{d} x$ is the fracture length in the fluid flow direction (Figure $4 \mathrm{~b}$ ). 


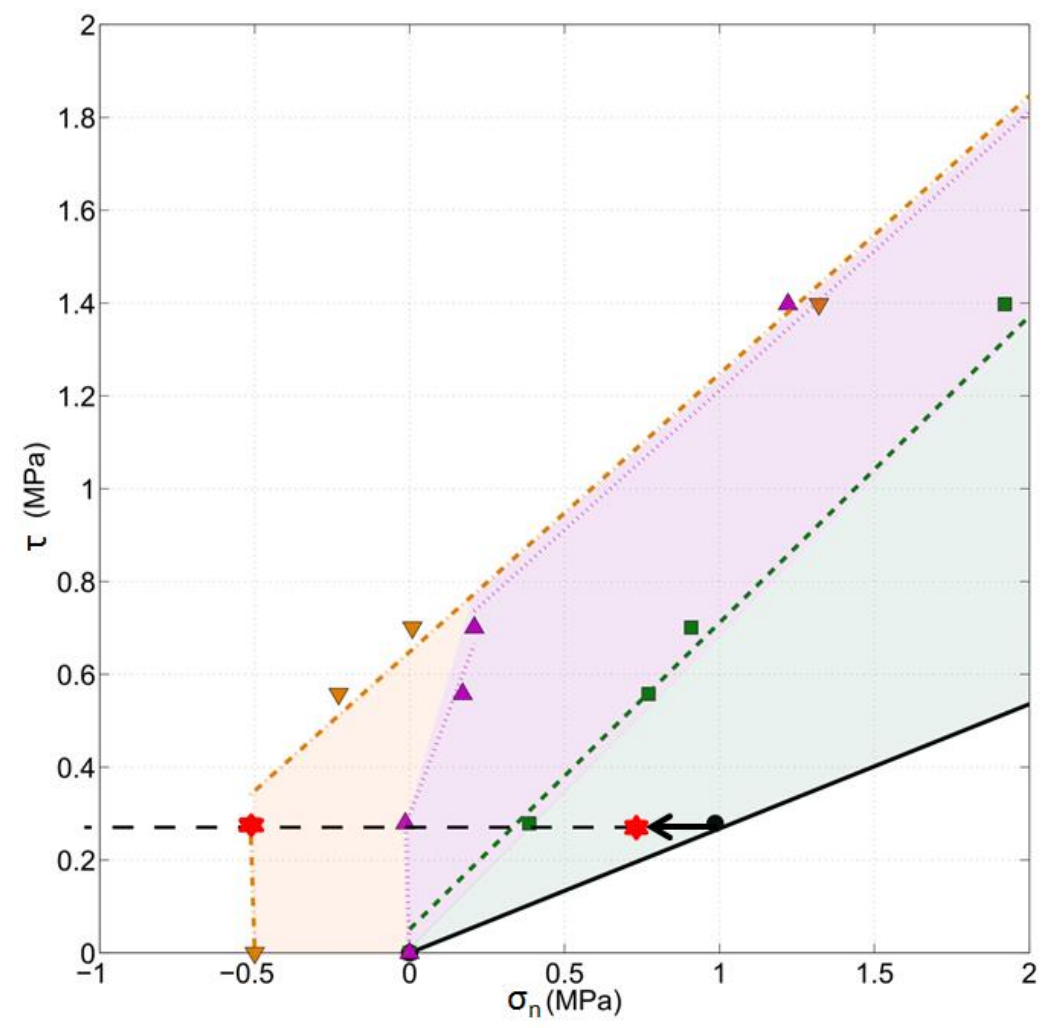

Figure 5. Equivalent failure envelopes for the fault plane: the black solid line corresponds to the homogeneous plane (case 1), the green dashed line to the case of higher friction heterogeneities (case 2), the purple dotted line to the case of higher friction (case 3), cohesion heterogeneities and the orange dash-dot line to the higher friction, cohesion, tensile strength heterogeneities (case 4). The black arrow indicates the direction of the evolution of the effective stress as the fluid pressure increases for each case. The two red starts correspond to the two configurations presented in Figure 7 for the frictional case, i.e. the failure envelope corresponds to the green dashed line.

For the four different cases, the evolution of the permeability value, which depends on the properties of the fracture plane, is followed by increasing the entrance fluid pressure P1 while keeping the same applied stress condition (dashed horizontal black line, starting from the black dot to the left, in Figure 5) and the same exit fluid pressure P2.

The plot of the results obtained with the numerical model for the four different configurations and combined with the Tournemire in-situ tests results are presented in Figure 6. The reference FOP value for the numerical model has been selected for case 3 , i.e. heterogeneous case (purple color) with friction and cohesion for the asperities. This value corresponds to the sudden increase of permeability whereas the global instability of the fracture plane is not reached yet (red star on the right in Figure 5).

For the homogeneous fracture plane (case 1), with the increase of fluid pressure, the evolution of the resulting permeability follows a linear evolution (black squares in the 
semilog plot) with no clear FOP transition as observed in the experimental tests (circles and diamonds in Figure 6).

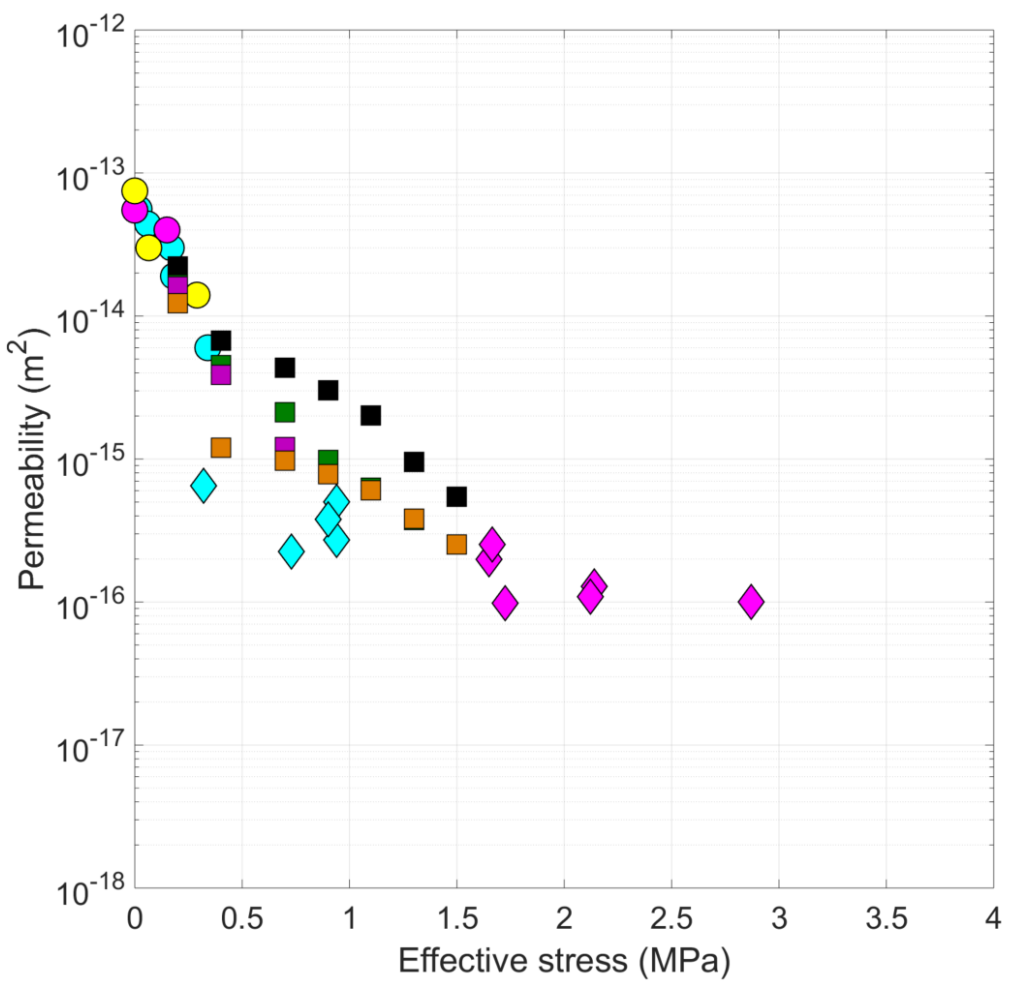

Figure 6. The permeability is represented as a function of effective pressure for all tests performed during the Tournemire tests (circles and diamonds). The numerical tests for the uniform fault plane (case 1, black squares), the heterogeneous fault plane with only frictional asperities (case 2, green squares), the heterogeneous fault plane with frictionalcohesive asperities (case 3, purple squares) and the heterogeneous fault plane with frictional-cohesive-tensile strength asperities (case 4, orange squares) are added for comparison.

When considering the heterogeneous fracture plane cases, the evolution of the permeability exhibits a two-step evolution (Figure 6) with a clear and sharp transition, corresponding to the FOP observed in the field tests. From the only frictional asperities (case 2, green squares in Figure 6) going through the frictional-cohesive ones (purple squares) to the frictional-cohesive-tensile strength rock bridges (orange squares), the FOP value is shifted to a lower effective stress, which means that the channeling process can remain active for higher fluid pressure values before fully opening the fracture plane.

From the respective FOP values of cases 2, 3 and 4, the permeability increases up to the one corresponding to a fully open fracture, i.e. permeability values above $10^{-14} \mathrm{~m}^{2}$. Below the FOP value, the fluid pressure does not yet trigger an overall mechanical instability of the fracture plane because the effective stress remains in the stable domains (Figure 5), but a substantial increase of the permeability is observed as the fluid is channeling between the heterogeneities (Figure 7).

Hence, the numerical model exhibits a sharp increase of the permeability comparable to the Tournemire observations, only if heterogeneities are taken into account. This sudden increase of permeability occurs for an effective stress corresponding to the FOP. This one has a different value depending on the in-situ stress conditions, which slightly differs on 
each side of the fault, but it corresponds to the same effective stress value. Below or around this value, the permeability is already increasing as the fluid propagates through channels in the fault plane. It is above the FOP value that with a certain amount of time delay, an overall mechanical response starts to be active.

For example, while increasing the fluid pressure in the heterogeneous frictional case (case 2 - green dashed linear failure envelop in Figure 5) for a fluid pressure generating an effective stress below the shear failure (right left star in Figure 5), the fluid is already channelling (Figure 7, left). As the fluid pressure increases, the effective stress reaches the failure limit, which triggers the irreversible slip of the fracture plane and the consequence is that the fluid propagates on the entire fracture surface (Figure 7, right).
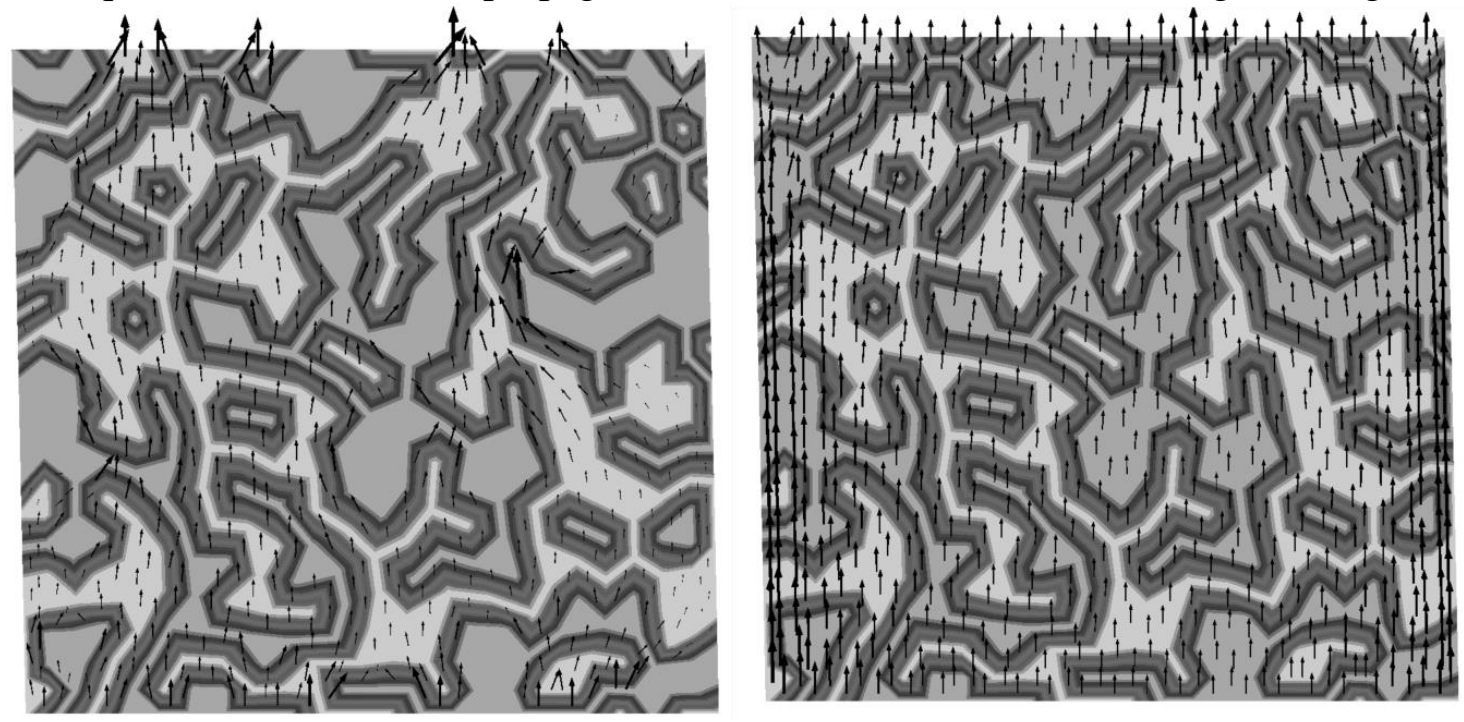

Figure 7. For the frictional case (case 2, green dashed failure envelope in Figure 5): (Left) below the FOP transition (right red star in Figure 5) as well as below the irreversible slip of the fracture plane, the fluid is channeling between the asperities and (right) well above the FOP and after the shear failure of the fracture plane (left red star in Figure 5), the fluid propagates and spreads all over the fracture zone. The fluid discharge rate is represented by arrows to show the local fluid flow direction and the asperities are represented by the darker grey zones.

In this case, the resulting permeability of the overall fault plane is close to $10^{-13} \mathrm{~m}^{2}$. For this range of permeability values, the Tournemire experimental tests can still exhibit a reversible or a limited plastic mechanical response when the fracture is hydraulically pressurized.

\section{Stress-dependent permeability analytical formulation}

As the effective stress applied to a fracture zone increases, the permeability decreases following distinct steps. First, near a null value of the effective stress, opened connected fractures draining the fluid exhibit a maximum permeability value. As the effective stress increases, the fluid is channeling as long as the rock bridges due to roughness, withstand the total stress loading. A new step occurs for the permeability drop when these bridges collapse and only connected micro-cracks can still overcome the intrinsic permeability due to the porosity of the medium. 
To express analytically this complex evolution of the permeability, an interesting concept is the stress-dependent relationship for rock porosity and permeability based on the TPHM for "Two-Part Hooke's Model" [Zheng et al., 2015]. In this formulation, the permeability is the sum of two terms: a first one describing the soft-behavior of the fracture, responsible for the significant permeability reduction for low effective stress levels, and a hard-behavior that involves the bulk volume of the rock body, when closure of the connected draining zones occurs. Based on this concept, the stress-dependent permeability $k$ is,

$$
k=k_{s}+k_{h}
$$

Where $k_{s}$ is related to the soft-behavior, which expresses the evolution of the permeability for low effective stress values as $k_{h}$ is related to the hard-behavior, which provides the permeability for high effective stress values.

For low values of the effective stress, the fracture porosity changes mainly control the variation of permeability according to a power law [David et al., 1994]. Because this porosity change also depends on the effective stress [Liu et al., 2009], according to an exponential law, $k_{s}$ can be expressed as,

$$
k_{s}=k_{0}\left(\gamma e^{-c_{f 0} \Delta \sigma}\right)^{m}
$$

Where $k_{0}$ is the permeability at the reference stress $\sigma_{0}, \Delta \sigma=\sigma_{\text {eff }}-\sigma_{0}$ is the differential stress between the effective stress and the reference stress, $c_{f 0}$ is the compliance of the fracture at the reference stress $\sigma_{0}, \gamma$ is the stress sensitivity coefficient and an exponent $m$. The values of the reference effective stress $\sigma_{0}$ with the corresponding $k_{0}$, are obtained from the pulse tests for a fluid pressure below the FOP (see Table 2 and Figure 8). The triaxial tests performed with the main loading direction perpendicular to the beddings at very low level of confinement, provided an estimate of the compliance value (Table 2) during the closing stage of the beddings [Bonnelye et al., 2017]. In order to decrease the amount of the fitting coefficient, $\gamma$ equals to one.

The value of $k_{l}$ will become negligible for $\Delta \sigma \gg \frac{1}{c_{f 0}}$ and it will be the hardbehavior term $k_{h}$, which will become the first order component of the global permeability. This part which corresponds to the closing of the draining channels, is based on the following formulation by Chen et al. (2015),

$$
k_{h}=k_{0} e^{\left[-3 C_{f} \Delta \sigma\right]}
$$

With the compliance $C_{f}$ now depending on the effective stress, such that,

$$
c_{f}=\frac{c_{f 0}}{\alpha \Delta \sigma}\left(1-e^{-\alpha \Delta \sigma}\right)
$$

Where $\alpha$ is the declining rate of fracture compressibility with the increasing effective stress.

With the parameter values presented in Table 2, we use Equation (2) to represent the evolution of the permeability for the Tournemire case (Figure 8). It is noteworthy that with $m=3, k_{l}$ corresponds to the cubic law [Witherspoon, 1980] (black dash curve in Figure 8). In this case, the analytical formulation fits the trend of the pulse tests but it is unable to reproduce the sharp curve of the permeability when the effective stress tends to 


\section{November 2019}

zero. Here, the exponent value needs to be much higher than 3 and we selected $m=30$ here (plain black curve in Figure 8). By doing so, the analytical formulation can reproduce the observed transition between the two regimes, i.e. channeling and the full aperture of the fracture.

Table 2. Values of the analytical formulation parameters to predict the permeability evolution

\begin{tabular}{ccccc}
\hline $\boldsymbol{k}_{\mathbf{0}, \boldsymbol{h}}\left(\mathbf{m}^{\mathbf{2}}\right)$ & $\boldsymbol{\sigma}_{\mathbf{0}}(\mathbf{M P a})$ & $\boldsymbol{c}_{\boldsymbol{f} \mathbf{0}}\left(\mathbf{M P a}^{-\mathbf{1}}\right)$ & $\boldsymbol{\alpha}(-)$ & $\gamma(-)$ \\
$4.22 \times 10^{-16}$ & 0.9 & 0.2 & 0.01 & 1.0 \\
\hline
\end{tabular}

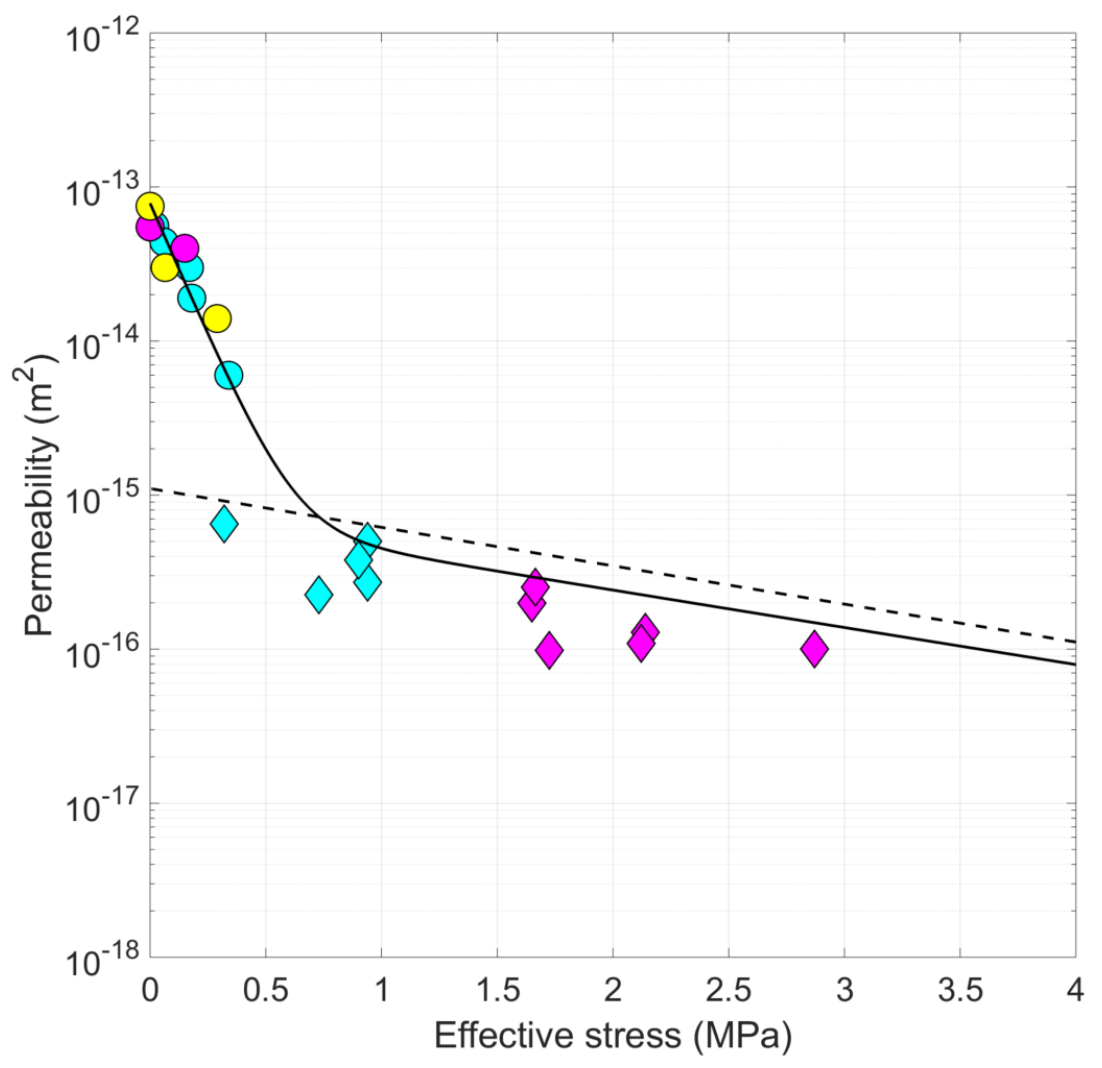

Figure 8. Permeability as a function of pressure in the injection borehole relative to the effective stress. Circles and diamonds correspond to the test carried out at Tournemire test site (see Figure 3 for details). The dashed line corresponds to Equation 2 with $m=3$ (cubic law). The plain black line corresponds to Equation 2 with $m=30$.

\section{Stress-dependent permeability for high effective stress values}

Unfortunately, we do not have any data covering the response of the fault zone in Tournemire for effective stress values higher than $3 \mathrm{MPa}$. Moreover, monitoring the permeability along a stress loaded fracture even at the laboratory scale is not currently common [Ye et al., 2018]. A report for the Canadian Nuclear Safety Commission [Nassery and Young, 2016] provided few values which can be considered here to assess the evolution of the permeability at high effective stress values, knowing that the permeability of the intact Tournemire shale is around $10^{-20}$ to $10^{-21} \mathrm{~m}^{2}$ [Boisson et al., 2001]. Note that, in opalinus clay rock, estimations of the MtTerri Main Fault 
permeability lead to values of $810^{-17} \mathrm{~m}^{2}$ to $10^{-18} \mathrm{~m}^{2}$ at relatively high effective stress values from field tests [Jeanne et al., 2018]. Going back to the triaxial tests performed on Tournemire shale [Nassery and Young, 2016], with a permeability regularly measured during the deformation, it was possible to get some data for high effective stress (Figure 9). Recall that scale effect can contribute to the variability of the permeability values and while taking every precaution in terms of analysis, the stress-dependent permeability relationship presented in Equation (2) has been used to integrate these new data by only choosing the declining rate of fracture compressibility $\alpha=0.01$ (Figure 9). A loglog representation has been chosen to well represent the evolution of the permeability versus the effective stress along the different scales.

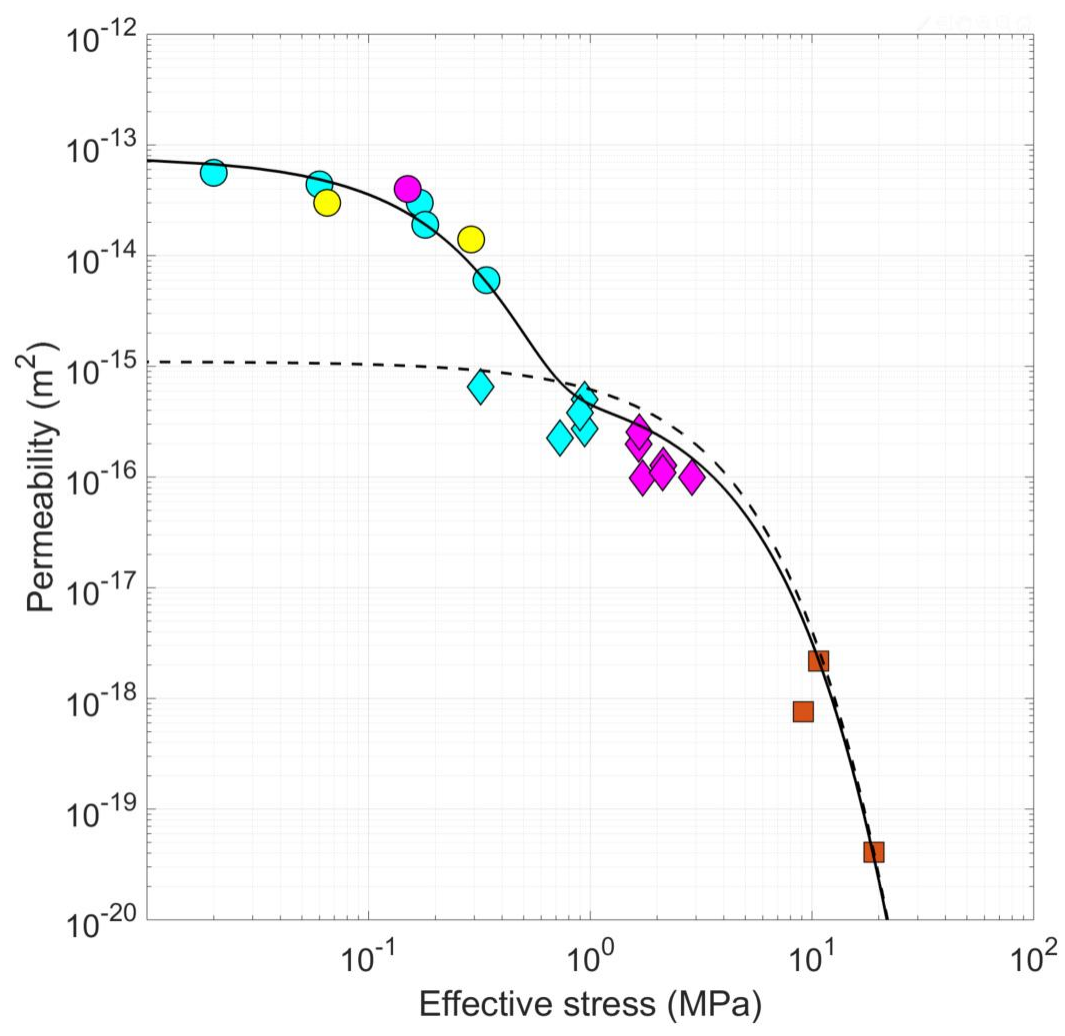

Figure 9. Permeability as a function of pressure in the injection borehole relative to the effective stress. Circles and diamonds correspond to the test carried out at Tournemire test site (see Figure 3 for details). The squares correspond to the laboratory tests on Tournemire samples [Nassery and Young, 2016]. The dashed line corresponds to Equation 2 with $m=3$ (cubic law). The plain black line corresponds to Equation 2 with $m=30$.

\section{Conclusions}

The hydromechanical behavior of faults in low permeability formations requires considering three conditions: (i) A quasi-sealed fault condition, with permeability comparable or slightly higher than the formation. (ii) An intermediate conductivity, which may apply to fault subject to limited or localized shear dilatancy as the fluid pressure reaches a subcritical pressure leading to channeling mechanisms. From our results, this permeability is expected to be 3 to 4 orders of magnitude higher than the permeability of the formation $\left(10^{-15}-10^{-14} \mathrm{~m}^{2}\right.$ for Tournemire shales). (iii) An open conduit condition that may apply to fault zones well above the FOP (Fracture Opening Pressure) leading to a 
plastic deformation of the fault zone. A TPHM for "Two-Part Hooke's Model" formulation type for the stress-dependent permeability can represent its complex evolution. However, a typical cubic law poorly reproduces the sharp transition of the permeability observed once the FOP is reached for very low effective stress value, in the Tournemire stress configuration. This sharp transition could be related to the presence of a differential stress, as a "softer" transition could be observed in case of hydrostatic loading.

The critical fluid pressure leading to the channeling mechanism in the damage zone along the fault is a key parameter that will determine the behavior of clay fault conduit, even if the fault is considered as inactive [Jeanne et al., 2018]. This has also been observed at the laboratory scale for fluid injection in a fault zone for different type of rocks, where the fluid was channeling at pressure much lower than the minimum value to trigger a mechanical instability [Nishiyama et al., 2014; Cuss et al., 2016].

Actually, several field observations suggest the existence of these flow paths in inactive fault zones that transmit fluids rapidly over large distances [Fabryka-Martin et al., 1997; Fairley \& Hinds, 2004; Campbell et al., 2003; Kluesner \& Brothers, 2016] and some of them have been observed to line up with regularly spaced pockmarks on the seabed [Ligtenberg, 2005; Gay et al., 2007]. These observations highlight the importance of weak zones along the faults, as suggested in the present model, thereby stressing the importance of focusing fault seal research based on geomechanical models good enough to provide accurate stress and pressure values. Since the fluid migration pathway can now be reasonably well detected using multiple seismic attributes and neural networks tools [Ligtenberg, 2005], associated to effective geomechanical models, this approach should greatly improve our understanding of the fluid migration mechanisms at the fault scale.

\section{Acknowledgments}

The authors would like to thank Total for funding this research project (contract FR00006163).

\section{References}

Bonnelye, A., Schubnel, A., David, C., Henry, P., Guglielmi, Y., Gout, C., Fauchille, A. L., \& Dick, P. (2017). Strength anisotropy of shales deformed under uppermost crustal conditions. Journal of Geophysical Research: Solid Earth, 122(1), 110129.

Boisson, J. Y., Bertrand, L., Heitz, J. F., \& Golvan, Y. M. L. (2001). In situ and laboratory investigations of fluid flow through an argillaceous formation at different scales of space and time, Tournemire tunnel, southern France. Hydrogeology Journal, 9, $108-123$.

Campbell, K., Wolfsberg, A., Fabryka-Martin, J., \& Sweetkind, D. (2003). Chlorine-36 data at Yucca Mountain: statistical tests of conceptual models for unsaturatedzone flow. Journal of contaminant hydrology, 62, 43-61.

Chen, Y. F., Zhou, J. Q., Hu, S. H., Hu, R., \& Zhou, C. B. (2015). Evaluation of Forchheimer equation coefficients for non-Darcy flow in deformable roughwalled fractures. Journal of Hydrology, 529, 993-1006. 
Cornet, F.H. (2000) Détermination du champ de contrainte au voisinage du laboratoire souterrain de Tournemire. Rapport du Laboratoire de Mécanique des Roches, Département de Sismologie, Institut de Physique du Globe de Paris, Rapport N98N33/0073

Cornet, F. H., Li, L., Hulin, J. P., Ippolito, I., \& Kurowski, P. (2003). The hydromechanical behaviour of a fracture: an in situ experimental case study. International Journal of Rock Mechanics and Mining Sciences, 40(7), 1257-1270.

Cuss, R. J., \& Harrington, J. F. (2016). An experimental study of the potential for fault reactivation during changes in gas and pore-water pressure. International Journal of Greenhouse Gas Control, 53, 41-55.

David, C., Wong, T. F., Zhu, W., \& Zhang, J. (1994). Laboratory measurement of compaction-induced permeability change in porous rocks: Implications for the generation and maintenance of pore pressure excess in the crust. Pure and Applied Geophysics, 143(1-3), 425-456.

Dick, P., Wittebroodt, C., Courbet, C., Sammaljärvi, J., Estève, I., Matray, J. M., SiitariKauppi M. Voutilainen \& Dauzères, A. (2016). The internal architecture and permeability structures of faults in shale formations. In The Clay Minerals Society Workshop Lectures Series (Vol. 21, No. 17, pp. 227-242).

De Barros, L., Daniel, G., Guglielmi, Y., Rivet, D., Caron, H., Payre, X., Bergery, G., Henry, P. Castilla, R., dick, P., Barbieri, E. \& Gourlay, M. (2016). Fault structure, stress, or pressure control of the seismicity in shale? Insights from a controlled experiment of fluid-induced fault reactivation. Journal of Geophysical Research: Solid Earth, 121(6), 4506-4522.

Fabryka-Martin, J. T., Flint, A. L., Sweetkind, D. S., Wolfsberg, A. V., Levy, S. S., Roemer, G. J. C., ... \& Duff, M. C. (1997). Evaluation of flow and transport models of Yucca Mountain, based on chlorine-36 studies for FY97. YMP Milestone Rep SP2224M3, Los Alamos National Laboratory, Los Alamos, New Mexico.

Fairley, J. P., \& Hinds, J. J. (2004). Rapid transport pathways for geothermal fluids in an active Great Basin fault zone. Geology, 32(9), 825-828.

Finkbeiner, T., Zoback, M., Flemings, P., \& Stump, B. (2001). Stress, pore pressure, and dynamically constrained hydrocarbon columns in the South Eugene Island 330 field, northern Gulf of Mexico. AAPG bulletin, 85(6), 1007-1031.

Gay, A., Lopez, M., Berndt, C., \& Seranne, M. (2007). Geological controls on focused fluid flow associated with seafloor seeps in the Lower Congo Basin. Marine Geology, 244(1), 68-92.

Guglielmi, Y., Cappa, F., Lançon, H., Janowczyk, J. B., Rutqvist, J., Tsang, C. F., \& Wang, J. S. Y. (2013). ISRM suggested method for step-rate injection method for fracture in-situ properties (SIMFIP): Using a 3-components borehole deformation sensor. In The ISRM Suggested Methods for Rock Characterization, Testing and Monitoring: 2007-2014 (pp. 179-186). Springer International Publishing.

Guglielmi, Y., Elsworth, D., Cappa, F., Henry, P., Gout, C., Dick, P., \& Durand, J. (2015). In situ observations on the coupling between hydraulic diffusivity and displacements during fault reactivation in shales. Journal of Geophysical Research: Solid Earth, 120(11), 7729-7748.

Guglielmi, Y., Birkholzer, J., Rutqvist, J., Jeanne, P., \& Nussbaum, C. (2017). Can fault leakage occur before or without reactivation? Results from an in situ fault reactivation experiment at Mont Terri. Energy Procedia, 114, 3167-3174.

Nguyen, T. S., Guglielmi, Y., Graupner, B., \& Rutqvist, J. (2019). Mathematical Modelling of Fault Reactivation Induced by Water Injection. Minerals, 9(5), 282. 
Gutierrez, M., Øino, L. E., \& Nygård, R. (2000). Stress-dependent permeability of a demineralised fracture in shale. Marine and Petroleum Geology, 17(8), 895-907.

Haney, M. M., Snieder, R., Sheiman, J., \& Losh, S. (2005b) A fault caught in the act of burping. Consortium Project on Seismic Inverse Methods for Complex Structures, 219.

Hao, F., Zhu, W., Zou, H., \& Li, P. (2015). Factors controlling petroleum accumulation and leakage in overpressured reservoirs. AAPG Bulletin, 99(5), 831-925.

Hawkes, C. D., McLellan, P. J., Zimmer, U., \& Bachu, S. (2004, January). Geomechanical Factors Affecting Geological Storage of CO in Depleted Oil and Gas Reservoirs. In Canadian International Petroleum Conference. Petroleum Society of Canada.

Henry, P., Guglielmi, Y., Morereau, A., Seguy, S., Castilla, R., Nussbaum, C., Dick, P., Durand, J., Jaeggi, D., Donze, F.V., \& Tsopela, A. (2016, February). Permeability-Fluid Pressure-Stress Relationship in Fault Zones in Shales. In AGU Fall Meeting Abstracts.

Itasca Consulting Group Inc. (Itasca) (2015) 3DEC (3-Dimensinal Distinct Element Code), version 5.2, Itasca, Minneapolis.

Jeanne, P., Guglielmi, Y., Rutqvist, J., Nussbaum, C., \& Birkholzer, J. (2018). Permeability variations associated with fault reactivation in a claystone formation investigated by field experiments and numerical simulations. Journal of Geophysical Research: Solid Earth, 123(2), 1694-1710.

Jones, R. M., \& Hillis, R. R. (2003). An integrated, quantitative approach to assessing fault-seal risk. AAPG bulletin, 87(3), 507-524.

Kluesner, J. W., \& Brothers, D. S. (2016). Seismic attribute detection of faults and fluid pathways within an active strike-slip shear zone: New insights from highresolution 3D P-Cable ${ }^{\mathrm{TM}}$ seismic data along the Hosgri Fault, offshore California. Interpretation.

Lefèvre, M., Guglielmi, Y., Henry, P., Dick, P., \& Gout, C. (2016). Calcite veins as an indicator of fracture dilatancy and connectivity during strike-slip faulting in Toarcian shale (Tournemire tunnel, Southern France). Journal of Structural Geology, 83, 73-84.

Ligtenberg, J. H. (2005). Detection of fluid migration pathways in seismic data: implications for fault seal analysis. Basin Research, 17(1), 141-153.

Liu, H. H., Rutqvist, J., \& Berryman, J. G. (2009). On the relationship between stress and elastic strain for porous and fractured rock. International Journal of Rock Mechanics and Mining Sciences, 46(2), 289-296.

Mildren, S. D., Hillis, R. R., Kivior, T., \& Kaldi, J. G. (2004). Integrated seal assessment and geologic risk with application to the Skua Field, Timor Sea, Australia.

Min, K. B., Rutqvist, J., Tsang, C. F., \& Jing, L. (2004). Stress-dependent permeability of fractured rock masses: a numerical study. International Journal of Rock Mechanics and Mining Sciences, 41(7), 1191-1210.

Nasseri, M. H. B., \& Young, R. P. (2016). Laboratory triaxial and permeability tests on Tournemire shale and Cobourg limestone, final report for Canadian Nuclear Safety Commission (CNSC) (Contract 87055-14-0209).

Nishiyama, S., Ohnishi, Y., Ito, H., \& Yano, T. (2014). Mechanical and hydraulic behavior of a rock fracture under shear deformation. Earth, Planets and Space, 66(1), 108.

Rivet, D., De Barros, L., Guglielmi, Y., Cappa, F., Castilla, R., \& Henry, P. (2016). Seismic velocity changes associated with aseismic deformations of a fault stimulated by fluid injection. Geophysical Research Letters, 43(18), 9563-9572. 
Shukla, R., Ranjith, P., Haque, A., \& Choi, X. (2010). A review of studies on $\mathrm{CO}_{2}$ sequestration and caprock integrity. Fuel, 89(10), 2651-2664.

Tsopela, A., Guglielmi, Y., Donze, F. V., De Barros, L., Henry, P., Castilla, R., \& Gout, C. (2016, February). Exploration of the role of permeability and effective stress transfer effects on Earthquakes Migration in a Fault Zone induced by a Fluid Injection in the nearby host rock: Experimental and Numerical Result. In AGU Fall Meeting Abstracts.

Tsopela, A., Donzé, F.V., Guglielmi, Y., Castilla, R., \& Gout, C. (2019). Hydromechanical reactivation of natural discontinuities: mesoscale experimental observations and DEM modeling. Acta Geotechnica, 14(5), 1585-1603.

Tremosa, J., Arcos, D., Matray, J. M., Bensenouci, F., Gaucher, E. C., Tournassat, C., \& Hadi, J. (2012). Geochemical characterization and modelling of the Toarcian/Domerian porewater at the Tournemire underground research laboratory. Applied Geochemistry, 27, 1417-1431.

Wiprut, D., \& Zoback, M. D. (2000). Fault reactivation and fluid flow along a previously dormant normal fault in the northern North Sea. Geology, 28(7), 595-598.

Witherspoon, P. A., Wang, J. S., Iwai, K., \& Gale, J. E. (1980). Validity of cubic law for fluid flow in a deformable rock fracture. Water resources research, 16(6), 10161024.

Ye, Z., Sesetty, V., \& Ghassemi, A. (2018, January). Experimental and numerical investigation of shear stimulation and permeability evolution in shales. In SPE Hydraulic Fracturing Technology Conference and Exhibition. Society of Petroleum Engineers.

Zheng, J., Zheng, L., Liu, H. H., \& Ju, Y. (2015). Relationships between permeability, porosity and effective stress for low-permeability sedimentary rock. International Journal of Rock Mechanics and Mining Sciences, 78, 304-318. 